Covered in: ERIH PLUS, CEEOL, Index Copernicus, CrossRef, CrossCheck, J-Gate, Google Scholar, Ideas RePeC, Econpapers, Socionet, KVK, WorldCat.

2020, Volume 8, Issue 2, pages: 83-104 | doi: 10.18662/lumenphs/8.2/47

\section{Conceptual \\ Delimitations \\ related to the \\ Philosophical \\ Approaches on Synthetic Biology}

\section{Olivia MACOVEI1}

${ }^{1} \mathrm{PhD}$ Student, Doctoral School of Social and Humanistic Sciences, Stefan cel Mare University of Suceava, Romania, oliviamacovei10@gmail.com

\begin{abstract}
Synthetic biology is an area of technological development and innovative scientific research at the crossroads between biology and technology (bioengineering), that aims to create artificial living systems, either by redesigning living systems that already exist in the natural environment, or by producing organic systems that are quasibiological, which emulate organic life. A number of research methods and technologies are incorporated in the development of synthetic biology, including genetic engineering, molecular biology and bio-molecular engineering, biophysics, chemical engineering, evolutionary biology, computer and computing engineering, genetics etc. The article aims to analyze the meanings of the term synthetic biology and the technological path that made the emergence of synthetic biology possible, the technological applications of synthetic biology, and starting from all this, to present a series of philosophical perspectives on synthetic biology.
\end{abstract}

Keywords: synthetic biology; philosopy of technology; technoethics.

How to cite: Macovei, O. (2020). Conceptual Delimitations related to the Philosophical Approaches on Synthetic Biology. Logos Universality Mentality Education Novelty: Philosophy \& Humanistic Sciences, 8(2), 83-104.

https://doi.org/10.18662/lumenphs/8.2/47 


\section{Introduction}

The idea of an "economy of promises" is the most appropriate expression of the techno-optimism that currently accompanies the research on synthetic biology, that aims, no more and no less, to create all sorts of organisms that meet social requirements or human desires and fantasies from new life forms to immortal life. Genetically modified or synthesized bacteria can help the emergence of new plant varieties that produce substances needed by the pharmaceutical industry, biofuels, or decontaminate the soil polluted by chemical or nuclear waste (Bensaude Vincent, 2015).

Techno-pessimists, on the other hand, cannot refrain from denouncing the risks that the "game of creation" and "the game of playing God" can bring (Dabrock, 2009), from the creation of unsustainable species that will disturb the ecological balance, to the irreversible damage of the environment or even of the human condition.

Given the interdisciplinary nature of the research in the field of synthetic biology, the scientific community has not yet reached a consensus on an unanimously accepted definition ( $\mathrm{Si}, \&$ Zhao, 2016).

A partial definition of the term synthetic biology, proposed by Zhao (2013) in a 2013 paper, is that synthetic biology is a series of researches on the design and construction of new or improved biological systems, based on a series of artificially constructed principles (Zhao, 2013) ${ }^{1}$. Tong and Zhao show that, in 2016, the synthetic biology-based industry exceeded $\$$ 10.8 billion. Along with the laboratories of Craig Venter - considered the father of synthetic biology - laboratories of major universities in the field are involved, such as MIT, the University of California, but also multinational companies - such as DuPont, BP, ExxonMobil, and start-up businesses, such as Synthetic Genomics, Amyris, Intrexon, Ginkgo Bioworks and Zymergen.

Zhao (2013) points out that there is a close link between synthetic and molecular biology, more specifically in what regards the research in the field of genome sequencing and the creation of synthetic DNA. Going beyond the applications related to genetic engineering, synthetic biology seeks, through its applications, the construction of biotechnologies that take into account artificial biological systems - whether at the molecular, cellular or multicellular level. As understood by the author, synthetic biology extends

\footnotetext{
${ }^{1}$ In English, in original: "design, construction, and characterization of improved or novel biological systems using engineering design principles".
} 
from the research aimed at creating artificial living structures - through molecular reconstruction of living systems - to technologies aimed at 3D printing of tissues and even organs. The bet is that synthetic biology will make it possible not only to mimic evolution in a post-Darwinian way, but reduced to a test tube level, but also to create genetic diversity in areas that do not exist in nature. The field of synthetic biology is considered to be one of the six basic fields of maximum interest for the contemporary American economy (Clark, \& Pazdernik, 2016).

Another definition of synthetic biology, offered by Priscilla Purnick and Ron Weiss, is that synthetic biology is a field of research at the crossroads between theoretical and applied research in biology, to which is added a constructive, specific engineering dimension (Purnick, \& Weiss, 2009). Synthetic biology is also defined as an emerging scientific discipline aimed at creating, controlling and reprogramming biological systems (Purnick, \& Weiss, 2009).

Practically, synthetic biology refers to any organism, living system, product or application that results from the introduction, assembly or modification of genetic material from a living organism (Vermeire, 2016, September 12).

In their attempt to see if and to what extent medicine and biology as cutting-edge contemporary sciences are prepared for the technological revolution involved in synthetic biology, Maxwell S. DeNies, Allen P. Liu, and Santiago Schnell in turn define synthetic biology as being a broad field that relies on the principles of engineering and computer science to create new biological systems or parts with new functions (DeNies, Liu, \& Schnell, 2020). The mentioned authors operate an epistemic distinction between fundamental and technological research, the first being focused on measuring and characterizing each component of an analyzed system, while the second is oriented towards the construction of the system starting from existing components and their recombination into naturally inaccessible structures. As such, through its specificity, synthetic biology can help biomedical research starting from the reconstruction of living systems in a way that does not exist in nature - but desirable for various therapeutic purposes.

One recent example is the construction of the anti-Covid vaccine, which is based on technologies derived from synthetic biology and involving the creation of a molecular mechanism of molecular synthesis analogous to the viral one, and mobilizing the body's immune response outside the presence of the virus, subsequently generating the immune response to any 
molecular synthesis of the same type - including the one generated by the presence of the Covid-19 virus (Dolgin, 2020, September 28).

DeNies et al. show that from a functional point of view, synthetic biology includes the design and construction of new biological entities, the reconstruction of existing biological systems in order to understand the mechanism and / or the redesign of existing biological systems (DeNies, Liu, \& Schnell, 2020). From a certain perspective, synthetic biology is similar to synthetic organic chemistry, its main objective being to capitalize on biological processes already known and technologically available, in order to create new materials or capabilities that do not exist in nature. From another perspective, synthetic biology can be seen as the next generation of biological reconstruction, as its methods allow researchers to answer deeper questions about molecular mechanisms, the origins of life and the design of minimal cells capable of capitalizing on the basic principles of life (DeNies, Liu, \& Schnell, 2020).

DeNies et al. divide the applications of synthetic biology into two areas, depending on the research strategies: synthetic biology conducted from top to bottom and the one conducted from bottom to top. The topdown approach is used in optogenetics (Adamantidis, Zhang, Aravanis, Deisseroth, \& de Lecea, 2007; Deisseroth, Feng, Majewska, Miesenböck, Ting, \& Schnitzer, 2006; Zhang, Wang, \& Boyden, 2006), for the biomolecular control of some cells, by stimulating photosensitivity. The bottom-up approach aims at assembling biomolecular and biological systems based on their constituents, including the creation of synthetic tissues (Johnson, March, \& Morsut, 2017; Yin, Mead, Safaee, Langer, Karp, \& Levy, 2016).

\section{Synthetic biology: historical path}

Although pursuits for synthetic biology date back to the mid-20th century, with the emergence and development of genetics, effective research in synthetic biology was developed after 2010, with the development of genome sequencing and mapping technology, through real-time PCR technologies (Saiki, Gelfand, Stoffel, Scharf, Higuchi, Horn, Mullis, \& Erlich, 1988).

The term synthetic biology was introduced by Stéphane Leduc (1910), with reference to physico-chemical theories on life and its spontaneous appearance, following evolutionary biology research that sought to explain the appearance of life in the "primordial organic soup". In 
1912, Stéphane Leduc published a volume entitled "Synthetic Biology" (Leduc, 1912).

The term synthetic biology acquires its current meaning in the work of the Polish geneticist Wacław Szybalski (Benner, Yang, \& Chen, 2011), entitled "In Vivo and in Vitro Initiation of Transcription" (Szybalski, 1974). The cited author is the one who differentiates between artificial and synthetic biologyand establishes that artificial biology includes quasi-living systems $^{2}$ or systems that are similar to live ones, while synthetic biology will represent - and already represents - artificially created living biological systems. Moreover, the authors V. Tetz and G. Tetz consider that a new definition of what "living" means should be proposed, by including in the concept such non-biological entities that have similar metabolic behaviors. The cited authors consider as a possible criterion for redefining what "living" means, the transmission of genetic information to similar structures (Tetz, \& Tetz, 2019).

In 2000, Michael B. Elowitz and Stanislas Leibler proposed the creation of biological circuits by combining genes with Escherichia coli cells (Elowitz, \& Leibler, January 2000). It is the merit of Craig Venter and his team $^{3}$ to bring synthetic biology to scientific and technological forefront, after the creation of the first replicated synthetic bacterial genome, namely the synthesis of a new genome based on a DNA synthesis of a bacterium (Mycoplasma myciodes) and its transplantation in a host cell (Mycoplasma capricolum) that becomes capable of self-replication and develops the characteristics of the original cell from which the DNA was extracted and replicated (Lachance, Rodrigue, \& Palsson, 2019).

In 2019 the creation of the first bacterial genome made entirely with the help of a computer was reported (Zurich, 2019, April 1), which biologically defines an entity (microorganism) that does not exist in nature, this being the first synthetic life form created and which modifies the coding of amino acids within the DNA (Venetz, Del Medico, Wölfle, Schächle,

\footnotetext{
2 At present, such systems are described that appear to reproduce and have their own metabolism, but are not included in the scientifically accepted definition of living, at least due to the fact that they are not carbon-based structures. (See the article $A$ new biological definition of life by Victor V. Tetz \& George V. Tetz - https://doi.org/10.1515/bmc-2020$\underline{0001)}$

${ }^{3}$ See the presentation of synthetic biology and its applications on the website of the J. Craig Venter Institute (JCVI) coordinated by Craig Venter where the first construction of an artificial genome took place - thus being considered the birth of synthetic synthetic biology: https://www.jcvi.org/research/synthetic-biology
} 
Bucher, Appert, Tschan, Flores-Tinoco, van Kooten, Guennoun, Deutsch, Christen, \& Christen, 2019).

\section{Technological applications of synthetic biology}

The technology and applications of synthetic biology fall into a wide range of areas of priority that are of interest to the global economy, such as medicine (Cachat, \& Davies, 2011) and medical technologies, the food industry, the chemical industry, but also ecology and biosecurity.

A 2005 report by NEST researchers classified the categories of activities specific to synthetic biology. These are:

1. Manufacturing devices:

- input type: cellular surface proteins, sensors, input elements;

- regulatory elements: inverters, logic gates, transcription, output type translations;

2. Design and synthesis systems:

- development of parts, devices, systems (standardized);

- construction of artificial cells;

- creation of synthetic organisms;

- nanotechnological materials;

- development of genomes using unnatural sources of nucleotides;

- in-cell synthesis of chemicals, materials and biopharmaceuticals;

3. Devices for cellular infrastructure:

- DNA synthesis and sequencing;

- microfluids;

- protein engineering, directed evolution;

- computer aided design tools: simulation of genetic circuits;

- noise and variation measurement.

According to the NEST group of researchers, synthetic biology will have a special impact and applicability in industry, research, education, in areas such as:

- biomedicine;

- synthesis of biopharmaceutical products;

- sustainable chemical industry;

- environment and energy;

- production of intelligent materials and biomaterials;

- security: bioterrorism monitoring (NEST High-Level Expert Group, n.d.). 


\section{Philosophical perspectives on synthetic biology}

Next, we will continue to focus on a number of contemporary dimensions regarding the philosophical approaches to synthetic biology. Although the issue is, we consider, topical and of interest for the philosophy of science in general and the philosophy of biology in particular, but also for the ethics of technologies, the philosophical literature addressing the theoretical-epistemic, ontological and ethical issues raised by synthetic biology is extremely limited, and philosophers still do not responde in large numbers to the invitation to question the meaning that synthetic biology poses for man and humanity, both from the perspective of its meanings for the human condition - from an anthropological, ethical and culturological perspective - and from the perspective of its ontological meanings - the nonlinearity of the evolution of the species in the context of synthetic biology, the artificialization of biology and the falsification / reconceptualization of the very idea of a living system.

Sara Green makes a connection between synthetic and systemic biology, both of which are recent interdisciplinary approaches to biology designed to improve our ability to understand, predict, and control living systems. Both fields broadly address the data provided by genetics and related fields, exploring new ways to approach biological and non-biological research - such as physics, chemistry, computer science and engineering (Green, 2019).

Research in the field of synthetic and systemic biology is, from an epistemic perspective, divided into fundamental theoretical research and applied technological research, but this distinction is not considered sufficient in the context of synthetic biology (O’Malley, 2009), its field being rather a new synthesis between the theoretical and the practical, as the engineering of biological systems leads directly to a better understanding of such systems and, conversely, the knowledge generated by synthetic biology is reflected back by new technologies, that further develop the field.

\section{The ontological perspective on synthetic biology}

From an onto-epistemological perspective, we must first of all refer to the previously mentioned approaches in this field - both a theoretical and practical - as research in engineering contributes to the fundamental research and vice versa.

The connection between synthetic biology and systemic biology highlighted by O'Malley is argued by the pragmatic approach in this field, as the specific epistemology is transdisciplinary and emerges from systems 
theory and systemic biology (Wolkenhauer, \& Mesarović, 2005). This systemic approach refers to issues such as the significance of the idea of life and, with it, the characteristics of living systems.

Although synthetic biology is considered to be a simple application of systemic biology, the creation of living structures through various changes in fundamental components of living systems operated at the biomolecular level brings to the forefront ontological references regarding the concept of life and its systemic definition as an anti-entropic system that exchanges substance and energy with the environment, thus ensuring its continuity and reproducibility (Coyne, 2020).

Lewis Coyne shows that synthetic biology aims to create living organisms or parts of organisms from standardized biological molecular assemblies, according to engineering principles known or developed in the process of biomolecular reconstruction.

The ontological component of Lewis Coyne's research seeks to answer the question "what kind of beings are the organisms obtained through synthetic biology?". The quoted author seeks to answer this question by making a comparison between natural, genetically modified organisms and machines. This distinction is considered to be necessary because most biologists and philosophers of biology frequently describe living organisms as "biological machines" (Coyne, 2020, pp. 43-55), and there is a reason to believe that organisms are actually a form of "machines" that have particular heuristic characteristics (Nicholson, 2013). This assumption about the machinist nature ${ }^{4}$ of living systems is criticized by Lewis Coyne because it undermines attempts to approach both human and non-human life from an ethical perspective. This approach to organisms as living machines finds its origin in the work of Descartes - who divides the cosmos into rex extensa and rex cogitans, i.e. in extended substance characterized by spatiality - and mental substance (Descartes, 2012). This distinction promotes the idea of a distinction in nature - also observed by Whitehead (1920) - which makes it impossible to hold the mind accountable for the actions of the body and vice-versa, even if the two substances are seen as inseparable.

The problem of substance communication is solved by Descartes through the intervention of the pineal gland, which is seen as a translator

\footnotetext{
${ }^{4}$ We avoided using the term mechanic using the term machine, precisely because at present we are talking about electronic computing machines that do not have a mechanical character, but also biological systems as living machines - in the sense shown by the quoted author.
} 
between the two types of substances, but this approach is considered unsatisfactory in terms of the problem of substance communication, which have different ontological natures.

In the history of Western thought, L. Coyne tells us that subjectivity is attributed only to humanity - that is, the adherence to rex cogitans - while other species function only in the empire of rex extensa (Coyne, 2020). The approach of living systems in the form of biological machines is therefore dependent on the Cartesian vision, to which, at most, a computational perspective is added. This computational perspective generates Ihde's idea (Ihde, 1979) of a technological mediation that alters the experience of the immediacy of the world, dividing the relationships in which human beings are involved in corporealized and hermeneutic relationships (Ihde, 1979).

A similar approach, stemming from the virtualization of the social space, belongs to the philosopher Antonio Sandu from Suceava, who considers that with this phenomenon of virtualization of the social space, we have reached a time of anthropological singularity, when rex cogitans will be able to communicate with other more or less similar thinking entities, based on purely noetic interactions (Sandu, 2020).

The "mechanistic" perspective on the world is gradually becoming a "machinist" perspective, under the impact of computational and communication technologies. The universe is a machine, or if it is not, it should be transformed into one and understood as such. Don Ihde believes that nowadays, technology mediates between itself and the world, by altering the experience of the immediate - amplifying or diminishing it - which, from an experiential and phenomenological perspective, is an alienation of both nature and subjectivity.

However, this approach is not new, as it can be applied to any form of technology, Ihde showing that, for example, glasses increase the subjective perception of the world, while clothes diminish the subjective perception of the environment - for example, in the form of ambient temperature perception (Ihde, 1979). However, new technologies not only alter the instrumentalized perception of the world, but also hermeneutic capacity - for example by inducing the ability to perceive realities otherwise hidden to the human eye and implicitly to human knowledge, as is the case of the atomic world. Connected with the perception of exteriority in a machinist manner, there is also the temptation to transform the biological into a machine-type otherness, as living beings are considered biological automatons.

Lewis Coyne rejects this technologization of the re-signification of the world, which, he believes, brings a teleologization of nature, because the 
objects in nature have a purpose in their quality as machines - and this scope is necessarily connected to the needs of human beings and the evolutionary needs of nature itself (Coyne, 2020, pp. 43-55). The Darwinian experience, Coyne tells us, denies the teleological approach originated in Aristotle's conception of biology and the eternity of species, which could thus play an instrumental role in human existence, being its adjuvants. With the acceptance of the evolution of species as an ontological foundation of biology, the transformations that biological entities undergo are undoubtedly useful without having a predetermined, predestined purpose, other than for evolutionary reasons. The goals of living entities are to exist and multiply thus being useful to their own species and those close to them in the food chain, without necessarily being designed as useful to the human species.

From this point of view, synthetic biology overturns this paradigm, because species created artificially through synthetic biology - including through genetic editing - are necessarily created with a goal directly aimed at the well-being of human beings. Of course, this approach leads some authors to refer to synthetic biology in the sense of playing God, creating or annihilating species at will (Dabrock, 2009; Van den Belt, 2009). The cited literature refers to the ethical perspective that we will address accordingly in the following chapters, but in this chapter we are particularly interested in understanding the ontological perspective raised by this new direction of development of science and technology - which is synthetic biology.

As L. Coyne points our, for Aristotle the purposes of an organism belong to the realm of immanence. Any organism exists, once, for itself, but at the same time for another (the human being), who can instrumentalize it either by the simple act of perception, as a perception of otherness, or by the act of use for ones own benefit (Aristotel, 2013). The conception of the Universe and the world as a living organism originates in Aristotelian thought, being influenced by the pantheistic perspective, but also by the teleology of thie following vision: the whole Universe, the whole nature is a living organism whose ultimate goal is the human being and its primary purpose is existence. This vision is replaced by the mechanistic one everything in the Universe is a machine - and at the same time by the computational one - everything in the Universe is an information - including biological - processor (Fontana, 2006; Sprevak, Copeland, \& Shagrir, 2017).

When an object is created for a particular purpose, its reason for being - according to the Aristotelian view - is the effective action of its creator, but the purpose of the machine itself is extraneous compared to the action of its creator, it is considered transcendent in the sense that it transcends the machine itself, but not in the sense of a creative divine 
power, but of a creative intent, which is separate from the created object. In this sense, a living being aims at its own existence, or more precisely has its purpose in itself - as long as we do not relate it to an external creator. The purpose of being for beings that naturally occur is to exist for themselves and for another, while the purpose of a synthetic entity is to exist for another and less for itself - which gives it the character of an artifact, in plain speking, of a synthetic biological creation.

However, we do not agree with Coyne's objections that the creation of a being through synthetic biology turns it into an object for another, at least as long as it does not nullify its reproductive capabilities through genetic intervention. A biological machine, even in its own reproductive process, works for itself, or more precisely in accordance with its own nature - according to its own genetic code -, but also for another - if such information is introduced into its genome.

At the current level of development of synthetic biology, when we speak of molecular synthesis or the creation of an artificial genome by specific CRISP procedures, the synthetic component - oriented towards a goal outside the created biological entity - is obvious (as in the case of Covid-19 vaccine, previously mentioned), while the "for itself" component remains obvious - but originated in the natural components of the recombinant genome (as is the case in Craig Vent's technological creations).

Speaking of the ontological perspectives mentioned above - the organic, mechanistic and computational ones - synthetic biology paves the way for a fourth ontological perspective: the organic - synthetic one. There are organic entities with concrete biological functioning, which can be at the same time computational structures, but also biological entities or, in a single phrase, biological computing machines. Extrapolating, as an ontological vision, a theory could appear on a computational but living synthetic Universe - where by "synthetic" we mean "created" -, which has its own capacity for calculation (and hence evolution), that is oriented towards a goal.

Of course, the purpose of this paper is not to make metaphysical speculations, and as such we limit ourselves only to indicating a possible philosophical development of this approach: whether synthetic biology will succeed in becoming the dominant paradigm in science, such as physics (which generated the mechanistic paradigm), or biology (which generated the mechanistic paradigm) and more recently of computer science (which generated the computational paradigm).

In fact, Craig Venter himself, the creator of the first synthetic bacterium (Mycoplasma laboratorium), when describing the research results, 
shows that this is the first self-replicating cell that exists on this planet and whose parent is a computer (Bensaude Vincent, 2015).

In turn, G. M. Church and E. Regis use the computational metaphor in reassessing living organisms as complex, programmable computing systems. This programmable character of biological entities invites the reprogramming and redesign of the whole world, the quoted authors stating that "just as computers are universal machines - in the sense that, given a proper program, they can simulate the activities of any machine - so can biological organisms be placed in the situation of universal constructors - in the sense that following convenient changes in their genetic code, they can be determined to produce any imaginable artifact". After all, a living organism is a prefabricated production system that, like a computer, is governed by a program - namely its own genetic code (Church, \& Regis, 2012).

Bernadette Bensaude Vincent believes that the redesign of life is the central goal of synthetic biology, but this new, transdisciplinary science has so far failed to develop a unanimous vision of what living organisms mean. However, we would add that the answers offered by synthetic biology, along with those in other branches of bio-nano-technologies, will not be able to be ignored when the question of redefining life is really raised, and especially of life as design which is a conscious act and not the act of an abstract, transcendent and omnipotent Creator, but of a transdisciplinary team that not only "deciphered the code of life", but currently aims to "shape the world atom by atom" (Bensaude Vincent, 2015) ${ }^{5}$ or respectively the "construction of organisms that will restore the world for us".

A critique of the computational perspective on synthetic biology is formulated by P. Luisi, who shows that molecular biosynthesis can lead to the disaggregation of the natural complexity of living systems due to the approximations of the genome subjected to nucleic acid synthesis (Luisi, \& Charabelli, 2011). In other words, biosynthesis requires an approximation of molecules as they exist in nature - in the sense of simplifying them and the links between molecular components -, and this approximation reduces the complexity of the new structure to a point that it is not found in nature and threatens the very existence of nature.

Another critique of the machinist approach to synthetic biology both of the one supporting that synthesized organisms are biological machines and of the one supporting that they are complex computational

\footnotetext{
${ }^{5}$ In English, in original: „shaping the world atom by atom.”

"In English, in original: „designing organisms that will remake the world for us".
} 
automata - is made by Iraj Nabipour, who insists on the difference between a living organism and a machine, even one of a complex biological nature. Nabipour also criticizes what he calls "knowledge-making practices" in synthetic biology, namely knowledge through the process of creating artifacts.

\section{The epistemological perspective on synthetic biology}

The epistemological perspective on synthetic biology is called primarily to answer the question of whether it is a science per se - and its subject of study is artificial life - or an advanced technological development correlated with computational technologies (Sullins, 1998). It is virtually impossible, says Christopher Langton, to study artificial life without reference to advanced computational technologies, as research on artificial life aims to synthesize life in a dynamic and complex way (Langton, 1987).

From an epistemological perspective, John Sullins places research on synthetic biology under the sign of the science of complexity and of chaos theory (Sullins, 1998, pp. 46-53). The science of complexity includes a number of disparate subfields, ranging from the field of electronic engineering or computers to medicine (Simbotin, 2020). This field, also called complex systems science, aims to create frameworks for understanding complex systems, including a range of complex, efficient and adaptable profiles. This science uses multiscale analyzes of evolutionary processes for physical, biological and social systems, while the so-called linear sciences favor a fragmentary approach to each component or aspect of the studied systems, the classical quantitative approach failing to interpret the causes and consequences of large-scale behaviors (Siegenfeld, \& BarYam, 2020).

Alexander F. Siegenfeld and Yaneer Bar-Yam show that complex systems can differ from each other not only in terms of the parts that comprise them, but also because of their role in the system and the interdependencies between them. Steam and ice are both composed of identical molecules, but the different interactions between the molecules make the two systems appear as substances with different properties. The properties that differentiate these states of aggregation cannot be deduced from the chemical structure of the water molecule, nor from its component parts. Likewise, the swirls of water that occur along rivers are an example of how the relationships between the components can give rise to different behaviors on a large scale, but also to self-organizing structures that occur 
not under the influence of external influences, but rather autonomously, in interactions within a system (Siegenfeld, \& Bar-Yam, 2020).

Complex interactions between the parts of a system can occur both at the molecular level and at larger levels, therefore the science of complexity can be used to describe both living systems and social systems (Guliciuc, 2014).

Returning to synthetic biology, the computational paradigm places it on the horizon of the science of complexity as a second-order machine (Langton, 1987, p.11). A number of criticisms of the use of complexity theory as a specific epistemological paradigm in synthetic biology are made by John Horgan in the article "From Complexity to Perplexity". Horgan believes that the study of artificial life, as well as the whole field of the science of complexity, seems to be based on a series of attractive but incomplete and unclear syllogisms, that show that there are a number of mathematical rules that can be followed by a computer to give rise to models of extreme complexity. The world itself contains such models of extreme complexity - and from this it could be deduced that there are a number of simple rules that emphasize the extremely complicated phenomena that exist in the world and therefore, with the help of truly high-performance computers, researchers can even extract those rules that generate complexity in nature (Horgan, 1995).

But this approach is not correct, says J. Horgan, because mathematical modeling, no matter how elegant, is comprised only of approximations of phenomena that occur in nature and their exact descriptions, and in terms of artificially constructed living systems - no matter how complex - these do not lead to an understanding of nature, but rather to its mimetic counterfeiting (Horgan, 1995).

Instead of studying natural systems, we construct parallel models that we superimpose on nature, confusing them with it. However, this critique is valid for any mathematical approximation and modeling and, as such, cannot in itself be a rejection of the epistemological approach of synthetic biology based on the theory of complexity, but only an emphasis on the explanatory limits of this theory regarding the possibility of modeling nature through artificial processes.

The scientific study of living organisms is saturated with metaphors about machines and their design, whether we are talking about computing machines or biological automata. Genes are considered the "plan" of an organism, the software according to which it works, therefore organisms are subjected to a reverse engineering process to discover their functionality, and living cells are compared to biochemical plants, assembly lines, transport 
systems, messaging circuits etc. (Boudry, \& Pigliucci, 2013). Although the notion of design is indispensable if we want to think about adaptations, and engineering analogies have considerable heuristic value, the authors Maarten Boudry and Massimo Pigliucci argue that these analogies are limited in several important respects. In particular, the analogy with man-made machines falters when it comes to molecular and genetic biology. Living organisms are much more "disordered" - in the same sense that this term is used in complexity theory - and less transparent to knowledge than manmade machines. Notoriously, "evolution is an opportunistic player" (Boudry, \& Pigliucci, 2013) - the term opportunistic player is taken from game theory, as a theory of rational choice (Cabon-Dhersin, \& Ramani, 2007) - thus "blindly stumbling" over "models" that no skilled engineer would professionally propose. Despite impressive technological innovation, the prospect of artificially designing new life forms from scratch has proved to be more difficult than the superficial analogy that the term "right software programming" would suggest (Boudry, \& Pigliucci, 2013).

The idea of applying simple engineering approaches to living systems and their genome - isolating functional components, designing new parts from scratch, recombining and assembling them into new life forms pushes the analogy with human artifacts beyond its limits. In the absence of an individual correspondence between genotype and phenotype, there is no simple way to implement new biological functions and design new life forms. Both the complexity of developing gene expression and the multiple interactions of genes and environments are serious obstacles to the "engineering" of a particular phenotype. Instead of genetically programming a desired trait from scratch, as the machine / engineering metaphor promises, researchers are making greater progress by co-opting natural selection to "search" for a suitable genotype or borrowing and recombining genetic material from existing life forms (Boudry, \& Pigliucci, 2013).

Another philosophical approach, both epistemic and ontological, to synthetic biology is that research in the field that appears as an interplay between molecular biology and computer science tends to create its own perspective on the very nature of life. From this perspective, Cécilia Bognon wonders whether the emergence of this new area of scientific research can be interpreted philosophically as an end to vitalism (Bognon, \& Wolfe, 2019). Vitalist theories in biology state the existence of a vital force, or at least of a specific force of life (Normandin, \& Wolfe, 2013), which clearly differentiates it, ontologically, from everything that is non-living, even if it is also in the form of a complex and self-adjusting system. 
The refusal of vitalism hides an ontological presupposition regarding the existence of a vital force that at the same time generates and transcends life itself and by which living organisms obtain this quality of being alive. However, synthetic products such as aminoacids or other complex molecules obtained in synthetic biology, even if they represent bricks of life in general, are not alive in themselves, but only constituents of the living systems in which they are incorporated. Only organisms constructed completely artificially, based on such synthetic molecules and which, assembled into cellular structures, behave as living entities, contrast with the idea of vitalism through a sui generis, ex nibilo appearance of life in non-living structures, under similar conditions (Venetz, et al., 2019) - at least partially with those that made possible the appearance of life in the "primordial organic soup" (Saladino, Šponer, Šponer, \& Di Mauro, 2018). To date, published research highlights genome sequencing and recombination of nucleotides in living bacterial structures, but no "engine of life" has been found in cells with fully edited DNA obtained from molecules that have never been part of previous genetic structures.

\section{The ethical perspective on synthetic biology}

Based on the Report of the Presidential Commission for the Study of Bioethical Issues on Synthetic Biology (2010), the need to create an ethical framework for evaluating emerging technologies can be emphasized, including genome sequencing, especially of the human genome, and the creation of genomes, synthetic organisms, genetic manipulation of species and construction of new germ lines by the irreversible modification of the genome of species etc.

Among the risks highlighted by the Cited Report, we can mention:

- the destruction of the genetic heritage of entire species - including and especially of humans;

- the emergence of hybrid and / or chimeric species, unsuited to any ecosystem but capable of endangering various ecosystems;

- the possibility of a biological threat, including to the human species, through the involuntary manipulation of biological material and its use for military or even terrorist purposes;

- the risks arising from the irreversible modification of reproductive technologies, by promoting synthetic biology and genetic editing through practices such as solo reproduction or CRISP;

- social inequities arising from access to advanced technologies and biomaterials - including the synthesis of biomolecules that do not exist in 
nature, that may constitute technological advantages but also threats to global security.

Practically, the responsibility of humanity towards the creation of new technologies that interfere in the processes of natural selection and the evolution of species can be invoked, thus annihilating complex ecological balances and having the possibility to lead to uncontrollable genetic mutations, both in the case of viral genetic material, hybridized with synthetic genetic material, as well as in the case of the genetic material underlying the DNA of various living cells that interfere with synthetic genetic material - either due to errors in the manipulation of their genetic content or due to the inability to predict the evolution of synthetic biological systems, which might have an evolution beyond any mathematical modeling that would allow the estimation of biological risks presented by the appearance of new species - which are partially or totally synthetic - and especially by their spread in ecosystems.

Last but not least, the ethical risks that arise in the case of excessive techno-optimism that can lead to exceeding the limits of social and ethical acceptability of technologies must be taken into account, especially as long as these limits are imprecisely outlined and there is no scientific or political agreement regarding these issues.

From our point of view, the report of the United States Presidential Commission for the Study of Bioethical Issues, while having the merit of drawing attention to the risks that technological development - including in the field of synthetic biology - may bring, fails to propose a model for the ethical evaluation of technologies that allows us to further identify the ethical risks that various technologies may involve and to establish principles and rules for an ethical decision regarding these technologies.

\section{Conclusions}

The foreseeable consequences of the development of synthetic biology - most of which have already been mentioned - seem to tip the balance in favor of the acceptability of these technologies, as long as synthetic biology itself cannot lead to the emergence of biotechnologies capable of significantly increase the quality of human life and life expectancy to offset the risks already mentioned.

However, synthetic biology can be an excellent starting point in generating new life forms that may be needed if it is intended to terraform other planets or celestial bodies, when a biological infusion of terrestrial biological material into primary organic structures or in synthesized 
biological compounds available on that planet can be achieved, and thus the constitution of a specific ecosystem. Synthetic biology and the synthesis of biomaterials can be a powerful adjuvant in understanding the mechanisms of structural changes in viral DNA, such as the evolution of Covid-19.

On the other hand, we appreciate that synthetic biology will not soon pass into the stage of production of standard synthetic organic materials and of biotechnologies capable of interacting with both living and non-living substances, of materials that may be needed in the construction of human-machine interfaces, or even of biocircuits capable of being incorporated into organic prostheses that may include nanotechnologies.

\section{References}

Adamantidis, A.R., Zhang, F., Aravanis, A.M., Deisseroth, K., de Lecea, L. (2007). Neural substrates of awakening probed with optogenetic control of hypocretin neurons. Nature, 450(7168), 420-424. https://doi.org/10.1038/nature06310

Aristotel. (2013). Despre suflet. Editura Univers Enciclopedic.

Benner, S.A., Yang, Z., \& Chen, F. (2011). Synthetic biology, tinkering biology, and artificial biology. What are we learning? Comptes Rendus Chimie, 14(4), 372387. https://doi.org/10.1016/j.crci.2010.06.013

Bensaude Vincent, B. (2015). Life by design: Philosophical perspectives on synthetic biology. BIO Web of Conferences, 4, 00015. https://doi.org/10.1051/bioconf/20150400015

Bognon, C., \& Wolfe, C. (eds). (2019). Philosophy of biology before biology. Routledge.

Boudry, M., \& Pigliucci, M. (2013). The mismeasure of machine: Synthetic biology and the trouble with engineering metaphors. Studies in History and Philosophy of Biological and Biomedical Sciences, 44(4), 660-668. http://dx.doi.org/10.1016/j.shpsc.2013.05.013

Cabon-Dhersin, M.-L., \& Ramani, S.V. (2007). Opportunism, Trust and Cooperation: A Game Theoretic Approach With Heterogeneous Agents. Rationality and Society, 19(2), 203-228. https://doi.org/10.1177/1043463107077391

Cachat, E., \& Davies, J. A. (2011). Application of Synthetic Biology to Regenerative Medicine. Journal of Bioengineering and Biomedical Sciences, $01(\mathrm{~S} 2)$. https://doi.org/10.4172/2155-9538.s2-003

Church, G.M., \& Regis, E. (2012). Regenesis, How Synthetic Biology will reinvent Nature and Ourselves. Basic Books.

Clark, D.P., \& Pazdernik, N.J. (2016). Synthetic biology: report to congress 2013. In David P. Clark, Nanette J. Pazdernik, Biotechnology (Second Edition), (pp. 419- 
Conceptual Delimitations related to the Philosophical Approaches on Synthetic ... Olivia MACOVEI

445). Academic Cell. https://doi.org/10.1016/B978-0-12-385015-7.00013$\underline{2}$

Coulter, I., Snider, P., \& Neil, A. (2019). Vitalism-A Worldview Revisited: A Critique Of Vitalism And Its Implications For Integrative Medicine. Integrative medicine (Encinitas, Calif.), 18(3), 60-73.

Coyne, L. (2020). The Ethics and Ontology of Synthetic Biology: a NeoAristotelian Perspective. Nanoethics, 14, 43-55. https://doi.org/10.1007/s11569-019-00347-2

Dabrock, P. (2009). Playing God? Synthetic biology as a theological and ethical challenge. Systems and synthetic biology, 3(1-4), 47-54. https://doi.org/10.1007/s11693-009-9028-5

Deisseroth, K., Feng, G., Majewska, A.K., Miesenböck, G., Ting, A., \& Schnitzer, M.J. (2006). Next-generation optical technologies for illuminating genetically targeted brain circuits. J Neurosci, 26(41), 10380-6.

DeNies, M. S., Liu, A. P., \& Schnell, S. (2020). Are the biomedical sciences ready for synthetic biology? Biomolecular Concepts, 11(1), 23-31. https://doi.org/10.1515/bmc-2020-0003

Descartes, R. (2012). Discurs asupra metodei. Editura Gramar.

Dolgin, E. (2020, September 28). Synthetic biology speeds vaccine development. Milestones 20. Retrieved from: https://www.nature.com/articles/d42859020-00025-4

Elowitz, M.B., \& Leibler, S. (January 2000). A synthetic oscillatory network of transcriptional regulators. Nature, 403(6767), 335-338. https://doi.org/10.1038/35002125

Fontana, G. (2006). Why we live in the Computational Universe. arXiv:physics, 0511157. https://doi.org/10.1063/1.2169325

Green, S. (2019). Philosophy of Systems and Synthetic Biology. In: Edward N. Zalta (ed.), The Stanford Encyclopedia of Philosophy (Winter 2019 Edition). Retrieved from: https://plato.stanford.edu/archives/win2019/entries/systems-syntheticbiology $/$

Guliciuc, V. (2014). Complexity and Social Media. Procedia - Social and Bebavioral Sciences. 149, 371-375. https://doi.org/10.1016/i.sbspro.2014.08.193

Horgan, J. (1995). From Complexity to Perplexity. Scientific American, 104.

Ihde, D. (1979). Technics and praxis. D. Reidel, Dordrecht.

Johnson, M.B., March, A.R., \& Morsut, L. (2017). Engineering multicellular systems: using synthetic biology to control tissue self-organization. Curr Opin Biomed Eng, 4, 163-73

Lachance, J.C., Rodrigue, S., \& Palsson, B.O. (2019). Minimal cells, maximal knowledge. eLife, 8, e45379. https://doi.org/10.7554/elife.45379 
Langton, C. G. (ed.). (1987). Artificial Life. Redwood City: Addison-Wesley.

Leduc, S. (1910). Théorie physico-chimique de la vie et générations spontanées. Nature, 86(410), 1911. https://doi.org/10.1038/086410a0

Leduc, S. (1912). La biologie synthétique, étude de biophysique. A. Poinat.

Luisi, P.P., \& Charabelli, C. (eds). (2011). Chemical Synthetic Biology. John Wiley \& Sons.

NEST High-Level Expert Group, Syntetic biology. Applying Engineering to Biology.

Retrieved from: http://www.synbiosafe.eu/uploads///pdf/EU-highlevelsyntheticbiology.pdf

Nicholson, D.J. (2013). Organisms $\neq$ machines. Stud Hist Phil Biol Biomed Sci, 44(4: part B), 669-678. https://doi.org/10.1016/i.shpsc.2013.05.014

Normandin, S., \& Wolfe, C. T. (2013). Vitalism and the scientific image: An introduction. In: S. Normandin \& C. T. Wolfe (editors), Vitalism and the scientific image in post-Enlightenment life science, 1800-2010. Springer.

O’Malley, M.A. (2009). Making Knowledge in Synthetic Biology: Design Meets Kludge. Biological Theory, 4(4), 378-389. https://doi.org/10.1162/BIOT a 00006

Presidential Commission for the Study of Bioethical Issues, New Directions: The Ethics of Synthetic Biology and Emerging Technologies (Washington, D.C.: PCBSI, 2010). Retrieved from: http://bioethics.gov/cms/synthetic-biology-report.

Purnick, P. E. M., \& Weiss, R. (2009). The second wave of synthetic biology: from modules to systems. Nature Reviews Molecular Cell Biology, 10, 410-422. https://doi.org/10.1038/nrm2698

Saiki, R.K., Gelfand, D.H., Stoffel, S., Scharf, S.J., Higuchi, R., Horn, G.T., Mullis, K.B., \& Erlich, H.A. (1988). Primer-directed enzymatic amplification of DNA with a thermostable DNA polymerase. Science, 239(4839), 487-491. https://doi.org/10.1126/science.239.4839.487

Saladino, R., Šponer, J. E., Šponer, J., \& Di Mauro, E. (2018). Rewarming the Primordial Soup: Revisitations and Rediscoveries in Prebiotic Chemistry. Chembiochem: a European journal of chemical biology, 19(1), 22-25. https://doi.org/10.1002/cbic.201700534

Sandu, A. (2020). Bioetica în criză sau criza bioeticii? O filosofie a societății medicalizate. Editura Lumen.

Si, T., \& Zhao, H. (2016). A brief overview of synthetic biology research programs and roadmap studies in the United States. Synthetic and Systems Biotechnology, 1(4), 258-264. https://doi.org/10.1016/j.synbio.2016.08.003

Siegenfeld, A.F., \& Bar-Yam, Y. (2020). An Introduction to Complex Systems Science and Its Applications. Hindawi, 2020, 6105872. https://doi.org/10.1155/2020/6105872 
Conceptual Delimitations related to the Philosophical Approaches on Synthetic ... Olivia MACOVEI

Sîmbotin, D.G. (2020). Limitele cunoaşterii. Perspective logico-epistemice. [Teza de abilitare]. Universitatea Tehnică din Cluj-Napoca, Centrul de Nord Baia Mare, Facultatea de Litere.

Sprevak, M., Copeland, J., \& Shagrir, O. (2017). Is the whole universe a computer? The Turing Guide: Life, Work, Legacy. Oxford University Press.

Sullins, J. (1998). Synthetic Biology: The Technoscience of Artificial Life. The Paideia Archive: Twentieth World Congress of Philosophy, 39, 1998, 46-53. https://doi.org/10.5840/wcp20-paideia199839704

Szybalski, W. (1974). In Vivo and in Vitro Initiation of Transcription. In: Kohn A., Shatkay A. (eds), Control of Gene Expression. Advances in Experimental Medicine and Biology, vol 44. Springer. https://doi.org/10.1007/978-1-4684-3246$\underline{6} 3$

Tetz, V.V., \& Tetz, G.V. (2019). A new biological definition of life. Biomolecular Concepts, 11(1), 1-6. https://doi.org/10.1515/bmc-2020-0001

Van den Belt, H. (2009). Playing God in Frankenstein's Footsteps: Synthetic Biology and the Meaning of Life. Nanoethics, 3, 257. https://doi.org/10.1007/s11569-009-0079-6

Venetz, J.E., Del Medico, L., Wölfle, A., Schächle, P., Bucher, Y., Appert, D., Tschan, F., Flores-Tinoco, C.E., van Kooten, M., Guennoun, R., Deutsch, S., Christen, M., \& Christen, B. (2019). Chemical synthesis rewriting of a bacterial genome to achieve design flexibility and biological functionality. PNAS, 116(16), 8070-8079. https://doi.org/10.1073/pnas.1818259116

Venetz, J.E., Del Medico, L., Wölfle, A., Schächle, P., Bucher, Y., Appert, D., Tschan, F., Flores-Tinoco, C.E., van Kooten, M., Guennoun, R., Deutsch, S., Christen, M., \& Christen, B. (2019). Chemical synthesis rewriting of a bacterial genome to achieve design flexibility and biological functionality. PNAS, 116(16) 8070-8079. https://doi.org/10.1073/pnas.1818259116

Vermeire, T. (2016, September 12). Oamenii de știință examinează potențialul și riscurile asociate biologiei sintetice. Comisia Europeană Sănătate publică Newsletter 143. Retrieved from: http://ec.europa.eu/health/newsletter/144/focus newsletter ro.htm

Whitehead, A.N. (1920). The concept of nature. Cambridge University Press, Cambridge

Wolkenhauer, O., \& Mesarović, M. (2005). Feedback Dynamics and Cell Function: Why Systems Biology is Called Systems Biology. Molecular BioSystems, 1, 14 16. https://doi.org/10.1039/b502088n

Yin, X., Mead, B.E., Safaee, H., Langer, R., Karp, J.M., \& Levy, O. (2016). Engineering Stem Cell Organoids. Cell Stem Cell, 18(1), 25-38. https://doi.org/10.1016/j.stem.2015.12.005 
Zhang, F., Wang, L.P., Boyden, E.S. (2006). Deisseroth, K. Channelrhodopsin-2 and optical control of excitable cells. Nat Methods, 3(10), 785-92.

Zhao, H. (2013). Synthetic Biology. Tools and Applications. Elsevier.

Zurich, E.T.H. (2019, April 1). First bacterial genome created entirely with a computer. ScienceDaily. Retrieved March 31, 2021 from www.sciencedaily.com/releases/2019/04/190401171343.htm 